\title{
CHEMICAL ANALYSIS OF LITSEA CUBEBA ESSENTIAL OIL HARVESTED FROM ARUNACHAL PRADESH, INDIA AND ESTIMATION OF MOSQUITO REPELLENT ACTIVITY WITH REFERENCE TO NETWORK ANALYSIS
}

\author{
NAYANMONI BORUAH ${ }^{1}$, SUDARSHANA BORAH ${ }^{1}$, PRIYANKA SARKAR ${ }^{2}$, HEMANTA KUMAR SHARMA ${ }^{1 *}$ \\ ${ }^{1}$ Department of Pharmaceutical Sciences, Dibrugarh University, Dibrugarh, Assam, India. ${ }^{2}$ Department of Bioengineering and Technology, \\ Gauhati University, Guwahati, Assam, India. Email: hemantasharma123@yahoo.co.in
}

Received: 01 March 2018, Revised and Accepted: 09 April 2019

ABSTRACT

Objective: Litsea cubeba is a medicinal plant indigenous to Southeastern Asia. The fruit of the plant is rich in essential oil. A study has been carried out to investigate on the chemical composition of essential oil of the plant harvested from Arunachal Pradesh and to find out its mosquito repellent activity.

Methods: The essential oil has been isolated from the fresh fruits by hydrodistillation and analyzed by gas chromatography-mass spectrometry. Compound-compound network analysis was carried out in SPSS software (IBM SPSS Statistics 20) followed by the construction of the network using Cytoscape 3.5.0. Mosquito repellent study was carried out using standard procedure.

Results: Citronellal (17.32\%), citronellol (13.85\%), nimbiol (9.35\%), and myrcenol (7.40\%) were the major constituents of the essential oil and the essential oil illustrated $3 \mathrm{~h}$ mosquito repellent activity against Aedes aegypti mosquitoes.

Conclusion: From this investigation, a significant difference could be observed in the essential oil composition from the previously reported data of other regional areas of Asia, and furthermore, the essential oil possesses significant mosquito repellent activity.

Keywords: Essential oil, Gas chromatography, Mass spectrometry, Aedes aegypti, Mosquito repellent.

(c) 2019 The Authors. Published by Innovare Academic Sciences Pvt Ltd. This is an open access article under the CC BY license (http://creativecommons. org/licenses/by/4. 0/) DOI: http://dx.doi.org/10.22159/ajpcr.2019.v12i5.32672

\section{INTRODUCTION}

Northeast India is a hub of medicinal plants. Various plants have been found with diverse medicinal properties in this region. Litsea cubeba is a medicinal plant indigenous to northeast India [1]. The fruit of the plant is used for various ethnomedicinal purposes. It is used for dizziness, in excessive perspiration, paralysis, and as an antidote to treat drunkenness [2,3]. Treatment of diseases by aborigines (Fig. 1) was reported using this plant [4]. Other species of the genus of Litsea are reported to possess biological activities [5]. Conventionally, this plant has been used for atopic eczema and coronary heart diseases [6,7]. According to the folklore of northeast India, the fruits of this plant are crushed, mixed with water, and sprinkled all over their houses to extend its perfumery smell all around their surroundings and repel mosquitoes. Gogoi et al. studied the antioxidant, anti-inflammatory, genotoxicity, and antimicrobial activities of L. cubeba essential oil (LC EO) harvested from Jorhat district, Assam [8]. As there is no scientifically reported data on the mosquito repellent activity of LC EO from northeast India, this study was carried out to analyze on the chemical composition of LC EO collected from Pasighat, Arunachal Pradesh, India, and to study on the mosquito repellent efficacy of the essential oil with reference to compound network analysis in the search of a novel mosquito repellent essential oil. Arunachal Pradesh, a state of richness in flora and fauna, is situated in the northeastern region of India and lies between the $27^{\circ} 33^{\prime} \mathrm{N}-29^{\circ} 22^{\prime} \mathrm{N}$ latitude and $95^{\circ} 15^{\prime} \mathrm{E}-97^{\circ} 24^{\prime} \mathrm{E}$ longitude with an elevation of 502 feet above mean sea level. This state has a disparity in topography and botanical diversity. Pasighat district is situated at $28.07^{\circ} \mathrm{N}-95.33^{\circ} \mathrm{E}$ of Arunachal Pradesh. It has a standard altitude of $153 \mathrm{~m}$.

Significant results were reported for biological activities of this plant in previous reports from other regional areas. The immunosuppressive effect of the essential oil of this plant has demonstrated a dose-dependent reduction in production of cytokine interleukin 12 (IL-12) and $\alpha$-tumor necrosis factor in lipopolysaccharide-stimulated bone marrow-derived dendritic cells. This study indicates the potential of LC EO for the treatment of autoimmune and inflammatory diseases [4]. Inhibition of expression of inflammatory mediators pro-inflammatory-IL-1 $\beta$ (pro-IL-1 $\beta$ ), inducible nitric oxide synthase, cyclooxygenase-2, and gene for encoding NACHT, leucine-rich repeat, and Pyrin domains-containing protein NLRP3 was observed with neral and geranial [9]. Citral from LC EO inhibited NLRP3 inflammasome activation and enhanced activation of nuclear factor E2-related factor 2 [10]. In a study, various extracts of the fruit of the plant have demonstrated insecticidal activity against Sitophilus zeamais. A chloroform extract of the fruits has exhibited fumigant, repellent activities against $S$. zeamais. Among the identified compounds of chloroform extract, chlorobutanol was reported as the compound having the strongest contact toxicity and fumigant toxicity [11]. Cell cycle arrest in lung cancer cells was reported using LC EO. LC EO was also reported to induce apoptosis [12]. LC EO from the fruits exhibited cytotoxic activity against human liver, oral, and lung cancer cell lines [13]. As essential oil of fruits of various plants of northeast India possesses promising biological activities, the authors have hypothesized that $L$. cubeba may possess potent mosquito repellent activity based on available data from traditional healers [14].

\section{MATERIALS AND METHODS}

\section{Collection and identification of plant material}

The fruits of L. cubeba were collected from a forest area of Pasighat, Arunachal Pradesh, India. The collected plant specimen was identified at Botanical Survey of India, Eastern Regional Centre, Shillong, India. The plant specimen was identified and authenticated as L. cubeba (Lour.) Pers. (Lauraceae) (No. HKSDU/2017/NB-01) through letter no. $\mathrm{BSI} / \mathrm{ERC} / \mathrm{Tech} / 2017 / 350$. All the samples were stored in the plastic bag at $8^{\circ} \mathrm{C}$ before use. 


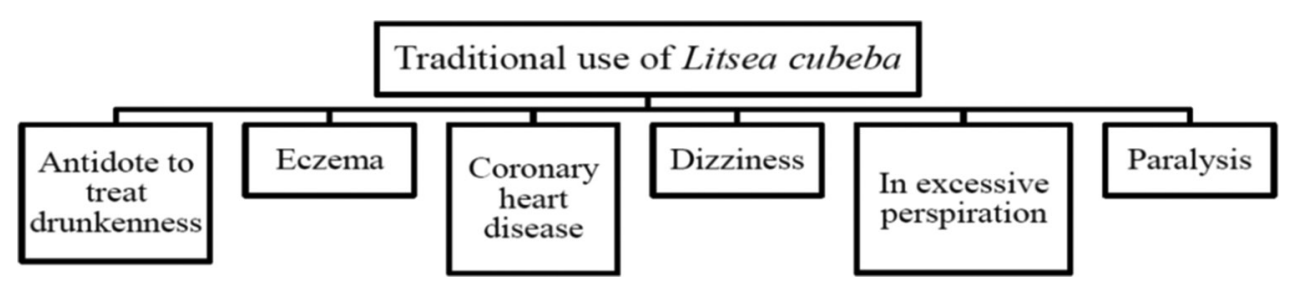

Fig. 1: Various traditional uses of Litsea cubeba plant

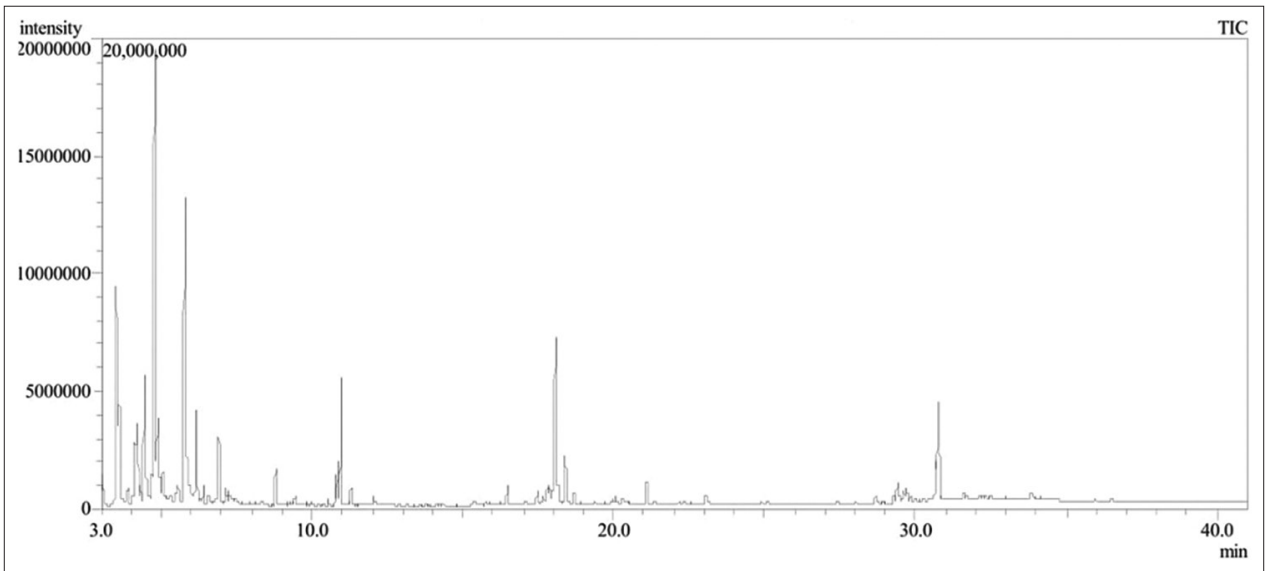

Fig. 2: Total ion chromatogram for L. cubeba essential oil using gas chromatography-mass spectrometry

\section{Extraction of LC EO}

Dried fruits (240 g) were ground using mortar and pestle. The ground material was subjected to hydrodistillation for $6 \mathrm{~h}$ using Clevenger-type apparatus. The essential oil was collected in a sterilized amber colored glass vial. The essential oil was stored at $4^{\circ} \mathrm{C}$ for further analysis [15].

\section{Yield of LC EO}

The yield of LC EO was calculated using the following equation:

$$
\text { Percentage yield of LC EO }=\frac{\text { Weight of extracted LC EO }}{\text { Weight of sample }} \times 100 \%
$$

\section{Gas chromatography and mass spectrometry}

Constituents of LC EO were separated and identified by gas chromatography-mass spectrometry (GC-MS) on an Agilent 5921A gas chromatograph hooked to an Agilent 5975 mass selective detector. GC was equipped with HP-5MS (30 $\mathrm{m} \times 250 \mu \mathrm{m} \times 0.25 \mu \mathrm{m})$. The GC settings were as follows: The initial oven temperature was held at $50^{\circ} \mathrm{C}$ for $1 \mathrm{~min}$ and ramped at $20^{\circ} \mathrm{C} / \mathrm{min}-280^{\circ} \mathrm{C}$ for $1 \mathrm{~min}$. The injector temperature was maintained at $250^{\circ} \mathrm{C}$. The sample $(10 \mu \mathrm{L}$, dilute to $1 \%$ with methanol) was injected in splitless mode. The carrier gas was helium at a flow rate of $1 \mathrm{~mL} / \mathrm{min}$. Spectra were scanned from $50 \mathrm{~m} / \mathrm{z}$ to $550 \mathrm{~m} / \mathrm{z}$ at two scans per second. Identification of constituents was made by comparing their mass spectra with those stored in NIST08 (NIST, Gaithersburg, MD, USA) and W8N08 (John Wiley and Sons, Inc., USA). Relative percentages for the individual constituents of the essential oil were determined from the GC peak area percentage report.

\section{Network analysis}

The co-occurrence network of the compounds obtained from the GC-MS analysis, bivariate correlation (Spearman's correlation) was carried out in SPSS software (IBM SPSS Statistics 20) followed by construction of the network using Cytoscape 3.5.0. The compounds, showing significant association $(p \leq 0.01)$ were taken for the analysis. Prefuse force-directed layout was considered for the visualization of the networks [16]

\section{Mosquito repellent activity study}

Mosquito repellent study was carried out as per the World Health Organization protocol WHO/HTM/NTD/WHOPES/2009.4 with trivial modifications in it. Two mosquito cages (size: $35-40 \mathrm{~cm}$ per side) each containing 200-250 non-blood-fed Aedes aegypti female mosquitoes were used. Mosquitoes were reared, maintained, and tested. Mosquitoes were host seeking, of uniform age, preferably 5-7 days post-emergence. Complete protection time and percentage protection were determined for $20 \%$ ethanolic LC EO solution. Complete protection time was calculated as the number of minutes elapsed between the time of repellent application and the first mosquito landing and/or probing. $1 \mathrm{~mL}$ of the $20 \%$ ethanolic N,N-diethyl$\mathrm{m}$-toluamide (DEET) solution was used as standard with the same amount (volume/volume) of the candidate repellent on the other arm. In both cases, treatments were applied to $\approx 600 \mathrm{~cm}^{2}$ area of the forearm skin between the wrist and elbow. To find out the complete protection time, $1 \mathrm{~mL}$ of $20 \%$ LC EO was applied to one arm and $1 \mathrm{~mL}$ of the DEET standard solution was applied to the other arm. After $30 \mathrm{~min}$, the repellent-treated arm was inserted into the appropriate cage and exposed for $3 \mathrm{~min}$ to determine landing and probing activity. Similarly, the DEET-applied arm was also exposed to determine landing and probing activity. This procedure was repeated for at least 30 min intervals and used consistently throughout the experiment until the first mosquito landing and probing [17].

\section{RESULTS}

\section{Yield of LC EO}

The percentage yield of LC EO extracted by hydrodistillation process was $2.485 \%$.

\section{Chemical composition of LC EO}

The total ion chromatogram is given as Fig. 2 and the chemical composition of LC EO is given in Table 1. The main constituents of the essential oil were found to be citronellal (17.32\%), and citronellol (13.85\%), nimbiol (9.35\%), myrcenol (7.40\%), caryophyllene oxide (4.13\%), citronellic acid (2.48\%) and isopulegol (2.30\%).

\section{Correlation network analysis}

The complex association of the compounds was studied and observed with positive link between citronellol and citronellal. Both compounds showed positive association with citronellic acid, caryophyllene, spathulenol, isopulegol, and melonal. Positive association of these 
Table 1: Identified constituents of the essential oil isolated from the fruits of Litsea cubeba indigenous to Arunachal Pradesh, India

\begin{tabular}{lll}
\hline S. No. & Name of the compound & Relative content (\%) \\
\hline 1 & Citronellal & $17.32 \pm 0.68$ \\
2 & Citronellol & $13.85 \pm 0.72$ \\
3 & Nimbiol & $9.35 \pm 0.34$ \\
4 & 1-(2,2,3,5,6-Pentamethylcyclohex-4-enyl)-9-(3,3,4-trimethylcyclohex-1-enyl)-3,6-dimethyl-6-ethenyl-dec-4-ene & $8.95 \pm 0.46$ \\
5 & Myrcenol & $7.40 \pm 0.38$ \\
6 & Caryophyllene oxide & $4.13 \pm 0.48$ \\
7 & 3-Tetradecyne & $3.40 \pm 0.64$ \\
8 & 3-Hexadecanol & $3.00 \pm 0.42$ \\
9 & 4,8,13-Duvatriene-1,3-Diol & $2.85 \pm 0.54$ \\
10 & Tetrahydro-2,2-dimethyl-5-(1-methylpropyl) furan & $2.75 \pm 0.16$ \\
11 & Melonal & $2.68 \pm 0.62$ \\
12 & Citronellic acid & $2.48 \pm 0.45$ \\
14 & Isopulegol & $2.36 \pm 0.36$ \\
15 & Caryophyllene & $1.02 \pm 0.52$ \\
16 & Spathulenol & $0.96 \pm 0.38$ \\
17 & a-Pinene epoxide & $0.70 \pm 0.48$ \\
18 & cis-Geraniol & $0.14 \pm 0.26$ \\
19 & Isopulegyl acetate & $0.42 \pm 0.72$ \\
20 & Citronellyl acetate & $0.36 \pm 0.44$ \\
21 & Monooxygenated terpenoids, sesquiterpenoids, and other organic compounds & $15.88 \pm 0.28$ \\
Total & & 100 \\
\hline
\end{tabular}

Oil sample size $(\mathrm{n})=3$. The relative content has been expressed as Mean $\% \pm \mathrm{SD}$

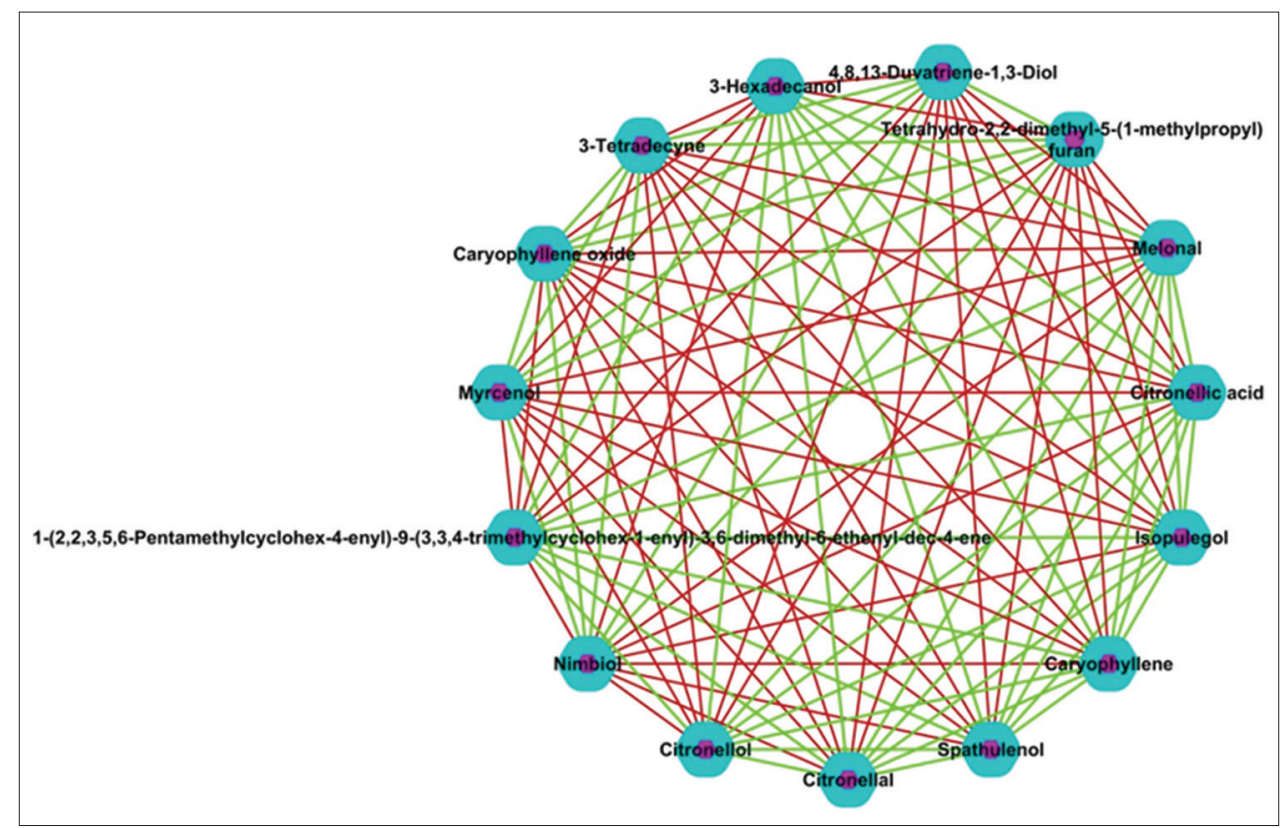

Fig. 3: Compound-compound network correlation for major constituents of Litsea cubeba. (The green dotted lines indicate positive correlation and the red dotted lines indicate negative correlation)

compounds results in synergistic action because positive association depicts structural similarities within the compounds as depicted in Fig. 3.

\section{Mosquito repellent activity study}

Complete protection time for standard 20\% DEET solution was found to be $6 \mathrm{~h}$. No landing or probing of mosquitoes was observed with $20 \%$ LC EO solution at $0 \mathrm{~min}, 30 \mathrm{~min}, 60 \mathrm{~min}, 90 \mathrm{~min}, 120 \mathrm{~min}$, and $150 \mathrm{~min}$. The first mosquito landing or probing efficacy was observed at $180 \mathrm{~min}$. This was the complete protection time for LC EO.

\section{DISCUSSION}

The composition of LC EO was significantly different from the previously reported data for the composition of the essential oil collected from fruits of $L$. cubeba of other regional areas in Asia.
Geranial (44.4-50\%) and neral (34.2-37.4\%) were reported as main constituents of LC EO collected from Sichuan, Yunnan, Hunan, Guizhou, Jiangxi, and Fujian Provinces of China [18]. Neral (63.75\%), limonene (7.38\%), methyl heptenone $(3.54 \%)$, and camphene $(3.12 \%)$ were reported as main constituents of LC EO collected from Southern areas of China [19]. Limonol (44.2\%), $\beta$-linalool (8.8\%), and 1,8-cineole (5.4\%) were reported as main components of LC EO collected from Bomi County, Tibet [20]. Geranial (27.49\%), neral (23.57\%), and D-limonene $(18.82 \%)$ were reported as the main constituents of LC EO collected from Guangxi, China [21]. This variation in chemical composition of the essential oil is due to the variation in their geographical location.

Mosquito repellent activity study of the essential oil demonstrated $3 \mathrm{~h}$ complete protection time which could be considered as a significant protection time. This potent activity is due to the presence of citronellol 
and citronellal as major chemical constituents in the essential oil. LC EO can be used for the development of eco-friendly sustained release mosquito repellent formulation.

This research work utilized the correlation network analysis for analyzing the activity of LC EO based on the constituents present in the essential oil. The use of correlation network analysis for analyzing activity of an essential oil was reported for the $1^{\text {st }}$ time in this paper.

\section{CONCLUSION}

It can be concluded that the composition of the essential oil from L. cubeba depends on its origin of the collection. The essential oil isolated from L. cubeba harvested from Pasighat, Arunachal Pradesh, India, possesses potentiality as mosquito repellent, and therefore, it can be used for the development of natural mosquito repellent formulation. Furthermore, biological activities of the essential oil can be explored based on the biological properties of the constituents present in the essential oil.

\section{ACKNOWLEDGMENT}

The authors are thankful to Botanical Survey of India, Eastern Regional Centre, Shillong - 793 003, India, for identification and authentication of the investigated plant and Director, Institute of Advanced Study in Science and Technology, Guwahati, Assam, for extending laboratory facility. Authors are thankful to Director, Indian Council of Medical Research, Dibrugarh, for extending facilities to carry out mosquito repellent study.

\section{AUTHOR'S CONTRIBUTIONS}

The first author (N.B.) initiated and conducted the research. The second author (S.B.) and the third author (P.S.) carried out network analysis for the constituents of the essential oil. The fourth author (H.K.S.) formulated the research hypothesis and reviewed the manuscript.

\section{CONFLICTS OF INTEREST}

Authors have no conflicts of interest to declare.

\section{REFERENCES}

1. Chaliha B, Lahkar L, Doley A, Kotoky R, Saikia SP, Nath SC, et al. Screening of some lesser known tree-borne oilseed plants from North East India for their oil content and major fatty acid components. Prostaglandins Leukot Essent Fatty Acids 2017;126:9-19.

2. Bhuinya T, Singh P, Mukherjee SK. Litsea cubeba medicinal values brief summary. J Trop Med Plants 2010;11:179-83.

3. Bhuinya T, Singh P, Mukherjee SK. Traditional uses of the Indian species of Litsea lam. Phytotaxonomy 2010;10:45-6.

4. Chen HC, Chang WT, Hseu YC, Chen HY, Chuang C, Lin CC, et al.
Immunosuppressive effect of Litsea cubeba L. Essential oil on dendritic cell and contact hypersensitivity responses. Int J Mol Sci 2016;17:13-9.

5. Kalita N, Kalita MC, Banerjee M. Reactive oxygen species generation in the antibacterial activity of Litsea salicifolia Leaf extract. Int J Pharm Pharm Sci 2016;8:189-93.

6. Anderson C, Lis-Balchin M, Kirk-Smith M. Evaluation of massage with essential oils on childhood atopic eczema. Phyther Res 2000;14:452-6.

7. Wang CY. The active principles of Litsea cubeba in the treatment of coronary heart disease. Zhong Yao Tong Bao 1985;10:30-2.

8. Gogoi R, Loying R, Sarma N, Mundaa S, Pandeya SK, Lala M. A comparative study on antioxidant, anti-inflammatory, genotoxicity, antimicrobial activities and chemical composition of fruit and leaf essential oils of Litsea cubeba Pers from North East India. Ind Crops Prod 2018;125:131-9.

9. Liao PC, Yang TS, Chou JC, Chen J, Lee SC, Kuo YH, et al. Antiinflammatory activity of neral and geranial isolated from fruits of Litsea cubeba Lour. J Funct Foods 2015;19:248-58.

10. Ka SM, Lin JC, Lin TJ, Liu FC, Chao LK, Ho CL, et al. Citral alleviates an accelerated and severe lupus nephritis model by inhibiting the activation signal of NLRP3 inflammasome and enhancing nrf2 activation. Arthritis Res Ther 2015;17:331

11. Zhang HJ, Zheng LH, Zhao K, Chen Y, Yi Z. Insecticidal activities of constituents of Litsea cubeba fruit extracts effective against the maize weevil (Coleoptera: Curculionidae). J Insect Sci 2017;17:1-6.

12. Seal S, Chatterjee P, Bhattacharya S, Pal D, Dasgupta S, Kundu R, et al. Vapor of volatile oils from Litsea cubeba seed induces apoptosis and causes cell cycle arrest in lung cancer cells. PLoS One 2012;7:e47014.

13. Ho CL, Jie-Pinge O, Liu YC, Hung CP, Tsai MC, Liao PC, et al. Compositions and in vitro anticancer activities of the leaf and fruit oils of Litsea cubeba from Taiwan. Nat Prod Commun 2010;5:617-20.

14. Majumder M, Sharma HK, Zaman K, Lyngdoh W. Evaluation of physico chemical properties and antibacterial activity of the essential oil obtained from the fruits of Zanthoxyllum acanthopodium DC. Collected from Meghalaya, India. Int J Pharm Pharm Sci 2014;6:543-6.

15. Li Y, Kong W, Li M, Liu H, Zhao X, Yang S, et al. Litsea cubeba essential oil as the potential natural fumigant: Inhibition of Aspergillus flavus and AFB1 production in licorice. Ind Crops Prod 2016;80:186-93.

16. Shannon P, Markiel A, Ozier O, Baliga NS, Wang JT, Ramage D, et al. Cytoscape: A software environment for integrated models of biomolecular interaction networks. Genome Res 2003;13:2498-504.

17. World Health Organization. Guidelines for Efficacy Testing of Mosquito Repellents for Human Skin. Geneva: World Health Organization; 2009.

18. Si L, Chen Y, Han X, Zhan Z, Tian S, Cui Q, et al. Chemical composition of essential oils of Litsea cubeba harvested from its distribution areas in China. Molecules 2012;17:7057-66.

19. Wang H, Liu Y. Chemical composition and antibacterial activity of essential oils from different parts of Litsea cubeba. Chem Biodivers 2010;7:229-35.

20. Yang Y, Jiang J, Qimei L, Yan X, Zhao J, Yuan H, et al. The fungicidal terpenoids and essential oil from Litsea cubeba in tibet. Molecules 2010;15:7075-82.

21. Yang K, Wang CF, You CX, Geng ZF, Sun RQ, Guo SS, et al. Bioactivity of essential oil of Litsea cubeba from China and its main compounds against two stored product insects. J Asia Pac Entomol 2014;17:459-66. 